KLEINE TEXTE FƯR VORLFSUNGEN UND ÜBUNGEN HERAUSGBGEBEN VON HANS LIETZMANN

\title{
SUPPLEMENTUM EURIPIDEUM
}

\author{
BEARBEITET
}

voN

\author{
H. v. A RNIM
}

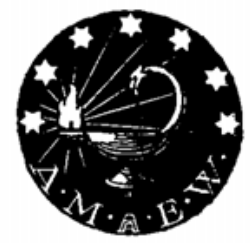

BON N

A. MARCUS UND E. WEBER'S VERLAG

I9I3 


\section{VORBEMERKUNG}

Dieses supplement enthält die reste verlorener euripideischer tragödien, die nach der zweiten auflage von Naucks Fragmenta Tragicorum aus papyri und anderen handschriften hinzugekommen sind. Damit das büchlein für seminarübungen über diese tragödien brauchbar wäre, mussten auch ihre früher bekannten bruchstücke mitaufgenommen werden. Nur bei dem als anhang mitgeteilten fetzen aus dem 'Archelaos' ist dies nicht geschehen. Satyros' 'Leben des Euripides', das eine reihe neuer bruchstücke enthält, ist als einleitung vorausgeschickt. Das grosse bruchstück der 'Melanippe Desmotis' wurde, obgleich schon bei Nauck in der zweiten auflage gedruckt, aufgenommen, weil inzwischen die ausgabe von Wilamowitz in den 'Berliner Klassikertexten' erschienen ist. Für die aufnahme des 'Phaëthon' war die vervollständigung der parodos durch den ebenda veröffentlichten Berliner papyrus entscheidend. Dass ich in der ausfüllung lückenhafter verse vielfach über die grenze des wissenschaftlich beweisbaren hinausging, wird die brauchbarkeit des buches nicht schädigen. Arthur Hunt's Fragmenta tragica papyracea (in der Bibliotheca Oxoniensis) erhielt ich noch rechtzeitig durch die güte des verfassers, um sie für meine arbeit benutzen zu können. Für die in den Hibeh-Papyri erhaltenen bruchstücke des euripideischen 'Oineus' gelang mir eine evident richtige zusammenfügung zweier fetzen, die nicht ohne bedeutung für die rekonstruktion ist. Mcine konjekturen sind mit A. bezeichnet.

Meinen kollegen, herrn Prof. Radermacher und herrn Prof. W.F. Otto, welche die freundlichkeit hatten, meine korrekturbogen mitzulesen und mir zahlreiche wertvolle bemerkungen und besserungen beisteuerten, möchte ich auch hier meinen herzlichen dank aussprechen.

Wien, 21. oktober 1912.

H. v. Arnim

\section{NACHTRÏGE}

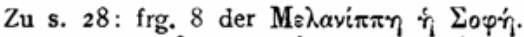

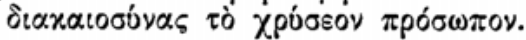

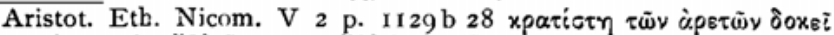

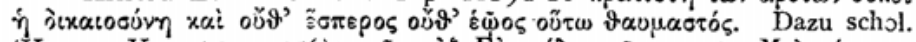

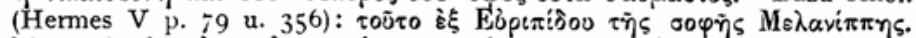

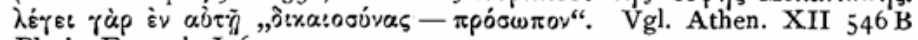
Plotin Ennead. I 6, 4

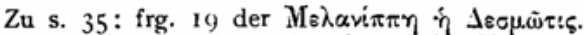

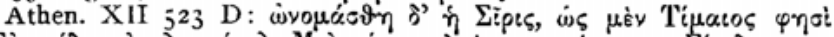

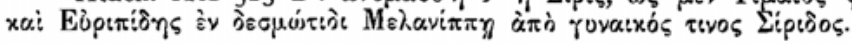

Zu s. 80 : frg. 8 des $\Phi \alpha$.

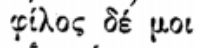

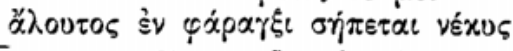

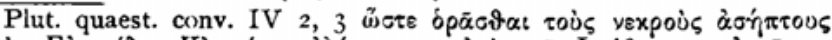

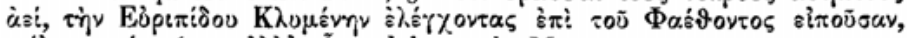

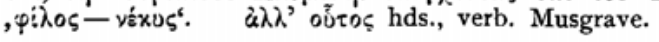

